\title{
Can the Open Label Placebo Rationale Be Optimized?
}

\author{
Uwe Heiss $^{1 *}$, Maayan Rosenfield ${ }^{2}$ and Michael H. Bernstein ${ }^{2}$ \\ ${ }^{1}$ Zeebo Effect, LLC, Burlington, VT, United States, ${ }^{2}$ School of Public Health, Center for Alcohol and Addiction Studies, \\ Brown University, Providence, Rl, United States
}

Keywords: placebo, open label placebo, mindfulness, placebo rationale, pain, chronic pain

\section{INTRODUCTION - THE ROLE OF THE RATIONALE IN OPTIMIZING PLACEBO TREATMENT}

OPEN ACCESS

Edited by:

Juliana Geremias Chichorro,

Federal University of Paraná, Brazil

Reviewed by:

Stefanie Helena Meeuwis,

Leiden University, Netherlands

Tiago Mestre,

The Ottawa Hospital Research Institute, Canada

*Correspondence:

Uwe Heiss

uweheiss@gmail.com

Specialty section:

This article was submitted to

Pharmacological Treatment of Pain,

a section of the journal

Frontiers in Pain Research

Received: 01 July 2021

Accepted: 17 August 2021

Published: 30 September 2021

Citation:

Heiss U, Rosenfield M and Bernstein MH (2021) Can the Open

Label Placebo Rationale Be

Optimized?

Front. Pain Res. 2:734882.

doi: 10.3389/fpain.2021.734882
The success of OLP treatment for chronic pain in clinical trials (1) holds promise for the eventual application of placebo in routine pain management. In preparation for the possibility of a clinical OLP roll-out, it is prudent to optimize OLPs for obtaining the maximum treatment effect. The first-author has previously identified three components (algorithm, rationale, placebo pill) of effective and safe placebo treatment design (2). As shown in Table S1, the algorithm refers to the identification of instances where an OLP may be beneficial and feasible. An algorithm could be implemented by posing a series of questions to the physician or healthcare provider, which would lead to a decision tree that determines if OLPs are suitable. The placebo pill refers to the physical features of the placebo. The focus of this article is the Rationale, which is the explanation given to the patient when administering an OLP.

\section{STATE OF THE ART: PLACEBO RATIONALE PRACTICE IN RESEARCH}

The OLP rationale refers to a verbal message wherein patients are told they are receiving a placebo and provided with an explanation regarding why the placebo may work. Almost every study that tested the effect of OLP included a rationale [though see (3)]. As such, patients do not just take a placebo, they are also told why taking a placebo might be efficacious. Both of these elements-the pill and the rationale-are important treatment components (4). In fact, in the only study to date where the presence of a rationale was manipulated, Locher et al. (5) found that OLPs with a rationale reduced experimentally-induced pain more than OLPs without a rationale. However, while this study suggests that including a rationale is important to maximizing the placebo effect, no prior research has examined OLP effects according to different types of rationales. In order to maximize the effect of OLPs, it is important to maximize the impact of the rationale.

In the initial Kaptchuk et al. (6) study, the OLP rationale entailed a 15-min discussion that centered on four points: "(1) the placebo effect is powerful, (2) the body can automatically respond to taking placebo pills like Pavlov's dogs who salivated when they heard a bell, (3) a positive attitude helps but is not necessary, and (4) taking the pills faithfully is critical.” (p. 2). As shown in Table 1, this 4-point discussion has become standard across OLP trials in clinical populations. With few exceptions $(7,8)$, all studies that examined the efficacy of OLPs outside a dose-extension model have used a rationale almost identical to or a close variation of that used in the Kaptchuk et al. study (9-17). Regarding the exceptions, patients in Kleine-Borgmann et al. (7) simply watched a video describing OLPs and those in Nitzan et al. (8) were told about past efficacy of placebos in studies and that they would likely help alleviate some depressive symptoms. 
TABLE 1 | Overview of placebo rationales in OLP studies with clinical samples.

\begin{tabular}{|c|c|c|c|c|}
\hline Reference & $N$ & Condition & $\begin{array}{l}\text { Standard } \\
\text { rationale }\end{array}$ & Rationale components \\
\hline Carvalho et al. (9) & 83 & Chronic low back pain & Yes+ & $\begin{array}{l}\text { Powerful, conditioning, positive attitude, compliance, video (discussing } \\
\text { past efficacy, individual success story) }\end{array}$ \\
\hline Hoenemeyer et al. (10) & 74 & Cancer-related fatigue & Yes & Powerful, conditioning, positive attitude, compliance \\
\hline Ikemoto et al. (11) & 48 & Chronic low back pain & Yes+ & Powerful, conditioning, positive attitude, compliance, past efficacy \\
\hline Kaptchuk et al. (6) & 80 & $\begin{array}{l}\text { Irritable bowel } \\
\text { syndrome }\end{array}$ & Yes & Powerful, conditioning, positive attitude, compliance \\
\hline Kelley et al. (12) & 20 & $\begin{array}{l}\text { Major depressive } \\
\text { disorder }\end{array}$ & Yes & Past efficacy, conditioning, positive attitude, compliance \\
\hline Kleine-Borgmann et al. (7) & 122 & $\begin{array}{l}\text { Chronic low back pain } \\
\text { (independent } \\
\text { replication) }\end{array}$ & No & Video (discussing past efficacy, individual success story) \\
\hline Kube et al. (13) & 54 & Allergic rhinitis & Yes+ & $\begin{array}{l}\text { Powerful, conditioning, positive attitude, compliance, create } \\
\text { expectation }\end{array}$ \\
\hline Nitzan et al. (8) & 38 & Unipolar depression & No & Past efficacy, create expectation \\
\hline Pan et al. (14) & 100 & Menopausal hot flushes & Yes & Powerful, conditioning, positive attitude, compliance \\
\hline Schaefer et al. (15) & 25 & Allergic rhinitis & Yes & Powerful, conditioning, positive attitude, compliance \\
\hline Schaefer et al. (18) & 46 & Allergic rhinitis & Yes & Powerful, conditioning, positive attitude, compliance \\
\hline Zhou et al. (16) & 40 & Cancer-related fatigue & Yes+ & $\begin{array}{l}\text { Powerful, conditioning, positive attitude, compliance, past efficacy, } \\
\text { create expectation }\end{array}$ \\
\hline
\end{tabular}

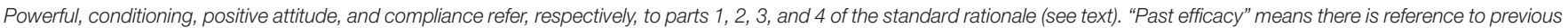

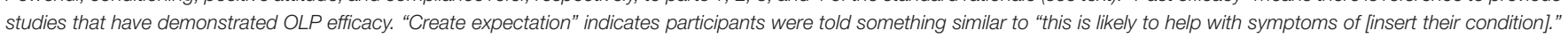

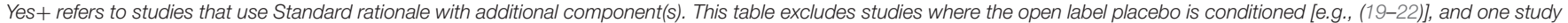
that included an OLP arm but was not designed to study OLP effects (3).

\section{THE POSSIBLE MODERATING POTENTIAL OF THE RATIONALE}

While the Algorithm component of OLP treatment design helps identify which cases or conditions might safely benefit from OLPs, the OLP Rationale and Placebo Pill enable, and possibly modify, the placebo response. The possibility that the OLP response may not just be enabled but moderated by the rationale is broadly consistent with research on deceptive placebos. According to Benedetti (23), "there is not one single placebo effect, but many" (p. 329). Indeed, the placebo effect depends on a variety of factors. For instance, consistent with Table S1 Row 3, placebos that are ostensibly branded are more effective at treating migraine than ostensibly generic placebos (24). Price also influences the placebo effect. In one study, placebos that supposedly cost $\$ 2.50$ per pill relieved pain in $85 \%$ of participants, while placebos allegedly costing $\$ 0.10$ only relieved pain in $61 \%$ of the sample (25). Of particular relevance to the discussion of a rationale, verbal instructions modify the placebo effect. Thomas (17) gave placebos to patients with a minor illness; 2 weeks later, those who were told that they would feel better in a few days improved more than patients who were not given positive expectations. In another study, a negative skin reaction was induced with a histamine skin prick (26). Afterwards, a placebo cream was applied, and those who were told the cream would help had a lower physiological reaction to the allergen than those who were told it would exacerbate the itching. In summary, the effectiveness of deceptive placebos is dependent on situational factors such as verbal instructions. OLP effectiveness may also be moderated by these variables, although no one has yet explicitly examined the role of competing instructions (i.e., rationales).

\section{AN APPROACH TO RATIONALE OPTIMIZATION AND INDIVIDUALIZATION}

The design of OLP studies thus far is based on rational persuasion conveying a stance that could be described as clinical and authoritative. However, patients' individual dispositions and receptiveness regarding information framing may differ. Some patients may be more receptive to intuitive guidance (i.e., mindfulness) rather than rational persuasion. Patients with an oppositional stance to scientific authority may benefit from being encouraged to suspend disbelief and find out for themselves by observing what happens during their OLP treatment. Therefore, to optimize OLP treatment, we propose two alternative types of rationales: Mindfulness and Suspension of Disbelief. Components of these rationales are provided in Table S2. The potential efficacy of the mindfulness rationale is supported by a meta-analysis of 38 RCTs, where patients assigned to a mindfulness condition reported less pain $(\mathrm{SMD}=0.32)$ compared to those in a control group (typically Treatment as Usual) (27). The potential efficacy of the suspension of disbelief rationale is supported by a pilot study (28) which indicated that while patients are skeptical about the effectiveness of OLPs, they would be willing to suspend disbelief (e.g., "If you say 'inert pills help you if you take 'em three times a day.. you'd be like 'wow, that's weird, but I'll try it... I guess he knows what he's talking about. Can't hurt me."). Thus, the two new rationales 
we propose are grounded in the results of earlier research. One consideration of the new aforementioned rationale conditions is that they incorporate guided imagery, which is an effective treatment on its own (29) that may fall under the broad umbrella of mindfulness. The imagery we utilize is OLP-specific; another potential approach would be to dismantle the effect of guided imagery from the proposed rationales. It is likely that each of these components are additive.

\section{CONCLUSIONS AND RECOMMENDATIONS}

No study so far has examined the efficacy of competing rationales, even though the rationale is an important intervention component and differences in preferences for placebo information have been noted (30). While the rationale developed by Kaptchuk et al., and used widely by others, has been effectively applied, it is possible that patients may respond more positively to other types of rationales. The natural next step in this line of research is to examine the impact of OLP across multiple rationales. Given the large body of work showing that OLPs are effective for chronic low back pain $(7,9,11)$ or other chronic pain conditions $(3,6)$, we suggest this is the appropriate clinical condition to examine rationale efficacy. We propose two additional rationales based on the concepts of mindfulness and suspension of disbelief to evaluate and optimize

\section{REFERENCES}

1. Kaptchuk TJ, Hemond CC, Miller FG. Placebos in chronic pain: evidence, theory, ethics, and use in clinical practice. Bmj. (2020) 370:m1668. doi: $10.1136 /$ bmj.m1668

2. Heiss U. The Placebo Cure: and Other Mind Body Effects. 2nd edition (2016).

3. Kam-Hansen S, Jakubowski M, Kelley JM, Kirsch I, Hoaglin DC, Kaptchuk TJ, et al. Altered placebo and drug labeling changes the outcome of episodic migraine attacks. Sci Transl Med. (2014) 6:218ra215. doi: 10.1126/scitranslmed.300 6175

4. Blease CR, Bernstein MH, Locher C. Open-label placebo clinical trials: is it the rationale, the interaction or the pill? BMJ. (2019) 25:15965. doi: 10.1136/bmjebm-2019-111209

5. Locher C, Nascimento AF, Kirsch I, Kossowsky J, Meyer A, Gaab J. Is the rationale more important than deception? A randomized controlled trial of open-label placebo analgesia. Pain. (2017) 158:23208. doi: 10.1097/j.pain.0000000000001012

6. Kaptchuk TJ, Friedlander E, Kelley JM, Sanchez MN, Kokkotou E, Singer JP, et al. Placebos without deception: a randomized controlled trial in irritable bowel syndrome. PLoS ONE. (2010) 5:e15591. doi: 10.1371/journal.pone.0015591

7. Kleine-Borgmann J, Schmidt K, Hellmann A, Bingel U. Effects of open-label placebo on pain, functional disability, and spine mobility in patients with chronic back pain: a randomized controlled trial. Pain. (2019) 160:28917. doi: 10.1097/j.pain.0000000000001683

8. Nitzan U, Carmeli G, Chalamish Y, Braw Y, Kirsch I, Shefet D, et al. Open-label placebo for the treatment of unipolar depression: results from a randomized controlled trial. J Affect Disord. (2020) 276:70710. doi: 10.1016/j.jad.2020.07.077

9. Carvalho C, Caetano JM, Cunha L, Rebouta P, Kaptchuk TJ, Kirsch I. Openlabel placebo treatment in chronic low back pain: a randomized controlled trial. Pain. (2016) 157:2766-72. doi: 10.1097/j.pain.0000000000000700
OLP treatment for chronic pain. Future studies with a clinical population could compare these rationales against each other, as well as to a condition where participants receive an OLP but without a rationale [as done by Locher et al. (5) with healthy volunteers]. This latter design would enable us to distill the effect of the Placebo Pill from the Rationale component [also see (4)]. We also suggest that patient's receptiveness to different rationales may vary with personality traits and patient preferences, marking the beginning of personalized OLP treatment.

\section{AUTHOR CONTRIBUTIONS}

$\mathrm{UH}$ and $\mathrm{MB}$ conceived the paper, wrote initial draft, and conceived of the mindfulness and suspension of disbelief rationales. MR created table and edited paper. All authors contributed to the article and approved the submitted version.

\section{FUNDING}

$\mathrm{MB}$ was funded by the National Institutes of Health K01DA048087.

\section{SUPPLEMENTARY MATERIAL}

The Supplementary Material for this article can be found online at: https://www.frontiersin.org/articles/10.3389/fpain. 2021.734882/full\#supplementary-material
10. Hoenemeyer TW, Kaptchuk TJ, Mehta TS, Fontaine KR. Open-label placebo treatment for cancer-related fatigue: a randomized-controlled clinical trial. Sci Rep. (2018) 8:2784-90. doi: 10.1038/s41598-018-20993-y

11. Ikemoto T, Ueno T, Arai YC, Wakao N, Hirasawa A, Hayashi K, et al. Openlabel placebo trial among japanese patients with chronic low back pain. Pain Res Manag. (2020) 2020:6636979. doi: 10.1155/2020/6636979

12. Kelley JM, Kaptchuk TJ, Cusin C, Lipkin S, Fava M. Open-label placebo for major depressive disorder: a pilot randomized controlled trial. Psychother Psychosomat. (2012) 81:312-4. doi: 10.1159/000337053

13. Kube T, Hofmann VE, Glombiewski JA, Kirsch I. Providing open-label placebos remotely-A randomized controlled trial in allergic rhinitis. PLoS ONE. (2021) 16:e0248367. doi: 10.1371/journal.pone.0248367

14. Pan Y, Meister R, Löwe B, Kaptchuk TJ, Buhling KJ, Nestoriuc Y. Open-label placebos for menopausal hot flushes: a randomized controlled trial. Sci Rep. (2020) 10:1-15. doi: 10.1038/s41598-020-77255-Z

15. Schaefer M, Harke R, Denke C. Open-label placebos improve symptoms in allergic rhinitis: a randomized controlled trial. Psychother Psychosomatics. (2016) 85:373-4. doi: 10.1159/000447242

16. Zhou ES, Hall KT, Michaud AL, Blackmon JE, Partridge AH, Recklitis CJ. Open-label placebo reduces fatigue in cancer survivors: a randomized trial. Support Care Cancer. (2018) 27:2179-87. doi: 10.1007/s00520-018-4477-6

17. Thomas KB. General practice consultations: is there any point in being positive? Br Med J (Clin Res Ed). (1987) 294:1200-202.

18. Schaefer M, Sahin T, Berstecher B. Why do open-label placebos work? A randomized controlled trial of an open-label placebo induction with and without extended informati on about the placebo effect in allergic rhinitis. PLoS ONE. (2018) 13:e0192758.

19. Sandler A, Bodfish J. Open-label use of placebos in the treatment of ADHD: A pilot study. Child. (2008) 34:104-10. doi: 10.1111/j.1365-2214.2007.00797.x

20. Sandler AD, Glesne CE, Bodfish JW. Conditioned placebo dose reduction: a new treatment in ADHD? J Dev Behav Pediatrics. (2010) 31:36975. doi: 10.1097/DBP.0b013e3181e121ed 
21. Morales-Quezada L, Mesia-Toledo I, Estudillo-Guerra A, O'Connor KC, Schneider JC, Sohn DJ, et al. Conditioning open-label placebo: a pilot pharmacobehavioral approach for opioid dose reduction and pain control. PAIN Rep. (2020) 5:e828. doi: 10.1097/PR9.0000000000000828

22. Flowers KM, Patton ME, Hruschak VJ, Fields KG, Schwartz E, Zeballos $\mathrm{J}$, et al. Conditioned open-label placebo for opioid reduction after spine surgery: a randomized controlled trial. Pain. (2021) 162:182839. doi: 10.1097/j.pain.0000000000002185

23. Benedetti F. Placebo effects: from the neurobiological paradigm to translational implications. Neuron. (2014) 84:62337. doi: 10.1016/j.neuron.2014.10.023

24. Branthwaite A, Cooper P. Analgesic effects of branding in treatment of headaches. Br Med J. (1981) 282:1576-8. doi: 10.1136/bmj.282.627 6.1576

25. Waber RL, Shiv B, Carmon Z, Ariely D. Commercial features of placebo and therapeutic. JAMA. (2008) 299:1016-7. doi: 10.1001/jama.299.9.1016

26. Howe LC, Goyer JP, Crum AJ. Harnessing the placebo effect: exploring the influence of physician characteristics on placebo response. Health Psychol. (2017) 36:1074-82. doi: 10.1037/hea0000499

27. Hilton L, Hempel S, Ewing BA, Apaydin E, Xenakis L, Newberry S, et al. Mindfulness meditation for chronic pain: systematic review and metaanalysis. Ann Behav Med. (2016) 51:199-213. doi: 10.1007/s12160-016-98 44-2

28. Bernstein MH, Fuchs N, Rosenfield M, Weiss AP, Blease C, Locher C, et al. Treating pain with open-label placebos: A qualitative study with post-surgical pain patients. J Pain. (2021). doi: 10.1016/j.jpain.2021.0 5.001. [Epub ahead of print].
29. Peerdeman KJ, Van Laarhoven AIM, Bartels DJP, Peters ML, Evers AWM. Placebo-like analgesia via response imagery. Eur J Pain. (2017) 21:136677. doi: 10.1002/ejp.1035

30. Smits RM, Veldhuijzen DS, Olde Hartman T, Peerdeman KJ, Van Vliet LM, Van Middendorp $\mathrm{H}$, et al. Explaining placebo effects in an online survey study: Does 'Pavlov'ring a bell?. PLoS ONE. (2021) 16:e247103. doi: 10.1371/journal.pone.0247103

Conflict of Interest: UH was the CEO and founder of Zeebo Effect, LLC.

The remaining authors declare that the research was conducted in the absence of any commercial or financial relationships that could be construed as a potential conflict of interest.

Publisher's Note: All claims expressed in this article are solely those of the authors and do not necessarily represent those of their affiliated organizations, or those of the publisher, the editors and the reviewers. Any product that may be evaluated in this article, or claim that may be made by its manufacturer, is not guaranteed or endorsed by the publisher.

Copyright (C) 2021 Heiss, Rosenfield and Bernstein. This is an open-access article distributed under the terms of the Creative Commons Attribution License (CC BY). The use, distribution or reproduction in other forums is permitted, provided the original author(s) and the copyright owner(s) are credited and that the original publication in this journal is cited, in accordance with accepted academic practice. No use, distribution or reproduction is permitted which does not comply with these terms. 